\title{
Event Volunteering: Gaya Hidup Kelompok Milenial (Studi Kasus Pada Volunteer Asian Games 2018)
}

\author{
Vanny Novella, Suzy S. Azeharie \\ vannynovella@gmail.com, suzya@fikom.untar.ac.id \\ Fakultas Ilmu Komunikasi Universitas Tarumanagara
}

\begin{abstract}
The use of new media especially by millennials in Indonesia has more or less changed the value and order of society. One interesting phenomenon is the event volunteering activities in which the dissemination of information is conveyed through new media. Events volunteering are increasingly in demand by millennials, particularly when 2018 Asian Games which is the event with the highest number of volunteers in Indonesia were held. This research aims to determine event volunteering as part of millennials' lifestyle, especially the 2018 Asian Games volunteers. This research uses a descriptive qualitative approach with a case study method. Data analyzed were obtained through interviews, observations, documentation studies and literature studies. Theories used in this research are communication theory, mass media, popular culture and lifestyle theory. The conclusion is event volunteering has become part of the millennials' lifestyle which can be seen from the feelings, attitudes and opinions of millennials that are relatively positive for event volunteering activities. In addition, the existence of commercialization in event volunteering's management is intended for the sake of public and event's sponsor. However, commercialization is also often found on several organizing committees and millennials activists in event volunteering.
\end{abstract}

Keywords: asian games 2018, event volunteering, lifestyle, millennial, new media,

\begin{abstract}
Abstrak
Tingginya penggunaan media baru atau new media khususnya oleh kelompok milenial di Indonesia sedikit banyak telah mengubah nilai dan tatanan di masyarakat. Salah satu fenomena yang menarik untuk diteliti adalah kegiatan event volunteering yang penyebaran informasinya disampaikan melalui new media. Kegiatan event volunteering yang diminati oleh kelompok milenial yakni penyelenggaraan Asian Games 2018. Event olahraga ini merupakan event dengan jumlah volunteer terbanyak di Indonesia. Penelitian ini bertujuan untuk mengetahui event volunteering sebagai bagian dari gaya hidup kelompok milenial khususnya volunteer Asian Games 2018. Penelitian ini menggunakan pendekatan kualitatif deskriptif dengan metode studi kasus. Data yang dianalisis diperoleh melalui wawancara, observasi, studi dokumentasi dan studi kepustakaan. Teori yang digunakan adalah teori komunikasi, media massa, budaya populer dan gaya hidup. Penelitian ini menyimpulkan bahwa event volunteering telah menjadi bagian dari gaya hidup kelompok milenial ditinjau dari aspek perasaan, sikap dan opini kelompok milenial yang relatif positif terhadap kegiatan event volunteering. Selain itu ditemukan pula adanya komersialisasi dalam penyelenggaraan event volunteering yang ditujukan untuk kepentingan publik dan sponsor event. Namun tindakan komersialisasi juga kerap ditemui pada beberapa pihak panitia penyelenggara dan kelompok milenial penggiat event volunteering.
\end{abstract}

Kata Kunci: asian games 2018, event volunteering, gaya hidup, milenial, new media, 


\section{Pendahuluan}

Nilai dan budaya manusia sebagai bagian dari kelompok masyarakat senantiasa mengalami perubahan. Salah satu penyebabnya adalah komunikasi yang menjadi sarana penyebaran nilai dan budaya. Pendapat ini sejalan dengan pernyataan Brent D. Ruben dan Lea P. Stewart bahwa tidak mungkin menyebarkan unsur-unsur budaya tanpa komunikasi dan teknologinya (Ruben dan Stewart, 2014).

Seiring dengan perkembangan teknologi saat ini media massa yang identik dengan media konvensional telah bergeser pada penggunaan new media sebagai salah satu agen perubahan di masyarakat. Di Indonesia jumlah pengguna internet dan media sosial telah mencapai 150 juta orang atau setara dengan 56 persen dari total populasi di Indonesia (https://datareportal.com/reports/digital-2019-indonesia diakses pada tanggal 20 September 2019 pukul 10.20 WIB). Jumlah tersebut didominasi oleh pengguna dari kelompok milenial di Indonesia, yaitu yang merupakan kelahiran tahun 1980 hingga 2000 (BPS, 2018).

Perkembangan dan penggunaan new media oleh kelompok milenial Indonesia telah membawa perubahan baru khususnya di bidang volunteering. Volunteering yang pada awalnya identik dengan kegiatan sosial dan membutuhkan komitmen jangka panjang kini telah berkembang dan muncul jenis kegiatan volunteering yang lebih lokal dan fleksibel dalam pelaksanaannya. Kegiatan ini dikenal dengan istilah event volunteering.

Pernyataan di atas didukung oleh pendapat Marc A. Musick dan Wilson yang menyatakan adanya perkembangan dalam dunia volunteering. Kini muncul bentuk volunteering baru yang bersifat lebih lokal dan berkaitan dengan acara-acara yang bersifat sporadik seperti festival musik, olimpiade olahraga, dll. Bentuk baru ini memberikan kesempatan bagi para volunteer untuk membantu dalam acara-acara tertentu tanpa harus tergabung dalam organisasi penyelenggara. Mereka tidak lagi dituntut untuk memberikan komitmen jangka panjang untuk suatu organisasi tertentu dan dapat membantu pada berbagai acara yang berbeda (Musick dan Wilson, 2008).

Minat dan antusiasme kelompok milenial Indonesia terhadap kegiatan event volunteering semakin meningkat khususnya pada penyelenggaraan Asian Games 2018. Event ini menjadi event dengan jumlah volunteer terbanyak yang pernah diselenggarakan di Indonesia. Berdasarkan data yang diperoleh dari Sekretaris Direktur Human Resources and Volunteer (HR\&V) Asian Games 2018, Tara Talitha total pendaftar mencapai 40.127 orang dan yang lolos seleksi menjadi volunteer pada saat games times Asian Games 2018 sebanyak 13.007 orang (wawancara dengan Tara Talitha di Plaza Semanggi, Jakarta Selatan pada tanggal 8 September 2019 pukul 19.15 WIB).

Seiring dengan peningkatan popularitas kegiatan event volunteering muncul indikasi kegiatan event volunteering dijadikan sebagai bagian dari gaya hidup kelompok milenial. Hal ini sesuai dengan tulisan Nelly dan Azeharie bahwa budaya populer secara tidak langsung mempengaruhi gaya hidup seseorang (Nelly dan Azeharie, 2018).

Berdasarkan pada latar belakang di atas, rumusan masalah dalam penelitian ini yaitu bagaimana event volunteering sebagai bagian dari gaya hidup kelompok milenial khususnya para volunteer Asian Games 2018?". Penelitian ini bertujuan untuk mengetahui event volunteering sebagai bagian dari gaya hidup kelompok milenial khususnya para volunteer Asian Games 2018. 
Gambar 1. Kerangka Pemikiran

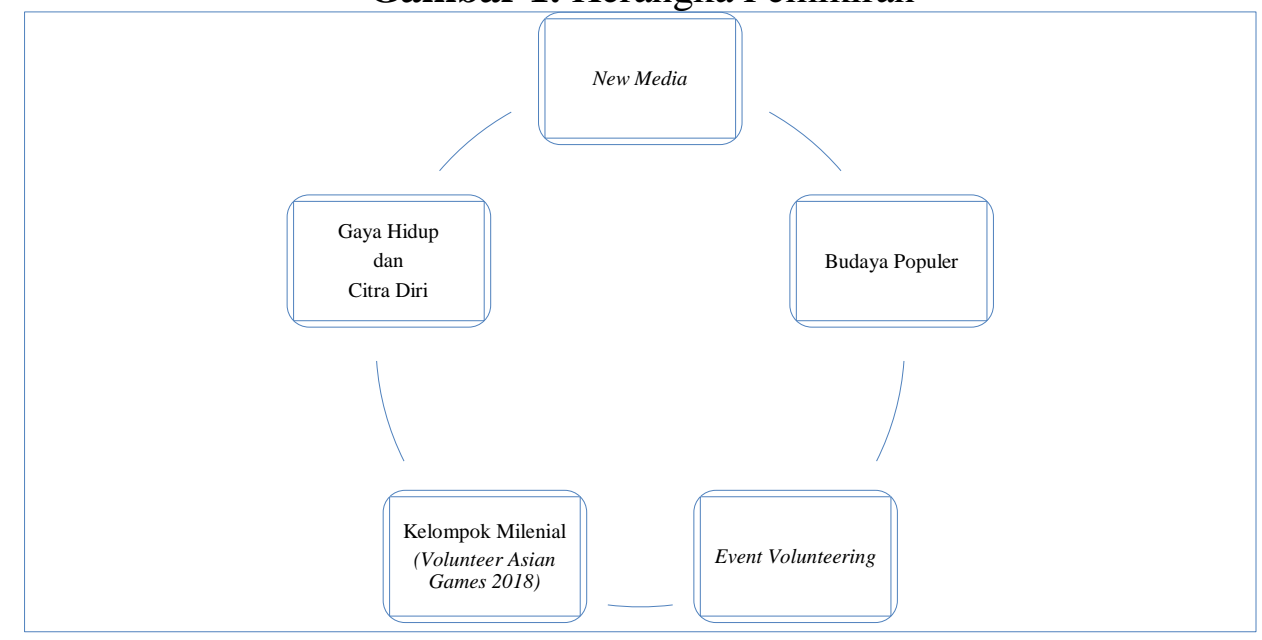

Sumber: Dokumentasi Pribadi (2019)

Gambar di atas adalah kerangka pemikiran yang menjadi dasar dalam penelitian ini. Teori yang digunakan untuk menganalisis data penelitian adalah teori komunikasi, media massa, budaya populer dan gaya hidup.

\section{Metode Penelitian}

Penelitian ini menggunakan pendekatan penelitian kualitatif secara deskriptif. Penelitian kualitatif bertujuan untuk memahami suatu fenomena sosial secara alami dengan menekankan pada proses interaksi dan komunikasi mendalam yang dilakukan peneliti dengan fenomena yang diteliti (Herdiansyah, 2014). Sedangkan penelitian yang deskriptif bertujuan untuk menghasilkan deskripsi dan gambaran fenomena secara lebih sistematis, faktual dan akurat (Nazir, 2011). Peneliti menggunakan metode penelitian studi kasus. Data yang dianalisis diperoleh melalui wawancara, observasi non-partisipan, studi dokumentasi dan studi kepustakaan. Peneliti melakukan wawancara kepada lima key informan dan tiga informan, antara lain:

1. Key informan pertama yaitu Laras Annisa Wahyuningtyas (24 tahun) yang pada saat invitation tournament menjadi volunteer Protocol Attendant dari Departemen International Relations. Lalu saat games times, Laras ditunjuk menjadi Venue Protocol Attendant Coordinator untuk daerah suburban. Laras telah aktif dalam kegiatan volunteering sejak di bangku Sekolah Menengah Pertama dan dapat terlibat hingga lebih dari sepuluh kegiatan event volunteering dalam setahun.

2. Key informan kedua yaitu Yasiinta Anggraeini (29 tahun) yang pada saat games times Asian Games 2018 menjadi koordinator volunteer venue Assembly Hall Senayan JCC dari Departemen Venue and Environment. Yasiinta telah aktif dalam dunia volunteering selama lebih dari sepuluh tahun dan telah banyak berpartisipasi dalam berbagai jenis kegiatan event volunteering.

3. Key informan ketiga yaitu Orryandhi Caksananda (30 tahun) yang menjabat sebagai koordinator volunteer di Departemen Venue and Environment dan bertanggung jawab mengkoordinasi volunteer-volunteer Venue and Environment di seluruh wilayah penyelenggaraan Asian Games 2018.

4. Key informan keempat yaitu Sonia Marcellina (28 tahun) yang menjadi volunteer Protocol Assistant dari Departemen International Relations pada saat invitation tournament Asian Games 2018. Pada saat games times, Sonia diangkat menjadi 
staff INASGOC yang bertugas mengkoordinir volunteer-volunteer NOC (National Olympic Committee) Assistant untuk tamu-tamu dari Asia Barat.

5. Key informan kelima yaitu Nandami Mahargina (35 tahun) yang menjadi volunteer NOC Assistant dari Departemen International Relations pada saat invitation tournament Asian Games 2018. Pada saat games times, Nandami diangkat menjadi staff INASGOC yang bertugas mengkoordinir volunteervolunteer NOC Assistant dan juga menjadi project manager untuk NOC Assistant manual book.

6. Informan pertama yaitu Tara Talitha (29 tahun) yang menjabat sebagai Sekretaris Direktur Human Resources and Volunteer (HR\&V) di Asian Games 2018.

7. Informan kedua yaitu Zulhasril Nasir (69 tahun) sebagai pengajar dan Guru Besar Ilmu Komunikasi di Fakultas Ilmu Sosial dan Ilmu Politik Universitas Indonesia.

8. Informan ketiga yaitu Dito Ariotedjo (29 tahun) sebagai pengamat gaya hidup milenial yang banyak menulis terkait perilaku anak muda Indonesia. Saat ini Dito menjabat sebagai Ketua Umum Organisasi Angkatan Muda Pembaharuan Indonesia (AMPI) dan Ketua DPP Golkar Bidang Inovasi Sosial.

\section{Hasil Temuan dan Diskusi}

Berdasarkan hasil observasi, studi dokumentasi dan wawancara ditemukan bahwa proses perekrutan volunteer untuk Asian Games 2018 dilakukan sebanyak dua kali. Pertama, untuk invitation tournament atau test event (yang dibuka dari tanggal 17 September sampai 23 Oktober 2017). Kedua, untuk games time atau main event (dibuka dari tanggal 18 Januari sampai 5 Maret 2018 dan diperpanjang lagi hingga tanggal 18 Maret 2018). Proses perekrutan dilakukan melalui website dan diumumkan melalui e-mail atau WhatsApp.

Media penyebaran informasi perekrutan volunteer Asian Games 2018, antara lain melalui media sosial, website, program campus visit dan konferensi pers yang mengundang media konvensional dan portal berita online. Dari wawancara dengan Tara diketahui bahwa media yang paling banyak membantu dalam proses perekrutan adalah media sosial khususnya akun Instagram resmi Asian Games 2018 dan program campus visit. Informasi perekrutan volunteer Asian Games turut disebarkan dengan bantuan dari akun-akun Instagram lain dengan jumlah pengikut yang banyak. Program campus visit dilakukan dengan mengunjungi dan mensosialisasikan perekrutan volunteer di beberapa kampus yang dekat dengan venue pertandingan (wawancara dengan Tara Talitha di Plaza Semanggi, Jakarta Selatan pada tanggal 8 September 2019 pukul 19.15 WIB).

Para volunteer Asian Games 2018 sebagian besar mengaku mendapatkan informasi perekrutan dari Instagram dan portal berita online. Sedangkan berdasarkan hasil observasi menunjukkan bahwa penyebaran informasi perekrutan juga dilakukan melalui broadcast WhatsApp group.

Berdasarkan hasil wawancara dengan seluruh key informan, semua sepakat bahwa Asian Games 2018 adalah kegiatan event volunteering paling bergengsi yang pernah diadakan di Indonesia. Perekrutan volunteer Asian Games 2018 telah membuka mata dan minat banyak orang terhadap kegiatan event volunteering.

Hal yang sama juga terlihat melalui hasil observasi dan studi dokumentasi pada salah satu akun Instagram penyebar informasi perekrutan volunteer @idvolunteering yang menunjukkan peningkatan minat dan antusiasme atas kegiatan volunteering. Hal ini terlihat dari angka engagement di @idvolunteering yang relatif meningkat setelah 
Vanny Novella, Suzy S. Azeharie: Event Volunteering, Gaya Hidup Kelompok Milenial (Studi Kasus Pada Volunteer Asian Games 2018)

Asian Games 2018 (https://www.instagram.com/idvolunteering/ diakses pada tanggal 28 Oktober 2019 pukul 18.33 WIB).

Tabel 1. Perbandingan Jumlah Engagement Unggahan Akun Instagram @idvolunteering

\begin{tabular}{clccc}
\hline \multicolumn{1}{c}{ Unggahan } & $\begin{array}{c}\text { Jumlah } \\
\text { Unggahan }\end{array}$ & $\begin{array}{c}\text { Jumlah } \\
\text { Rata-rata } \\
\text { Likes }\end{array}$ & $\begin{array}{c}\text { Jumlah } \\
\text { Rata-rata } \\
\text { Komentar }\end{array}$ \\
\hline 1. $\quad \begin{array}{l}\text { Sebelum Asian Games } \\
\text { (25-27 Agustus 2017) }\end{array}$ & 8 & 36 & 1 \\
2. $\quad \begin{array}{l}\text { Asian Games 2018 (28 Agustus } \\
\text { 2017-3 Maret 2018) }\end{array}$ & 7 & 127 & 10 \\
3. $\quad \begin{array}{l}\text { Setelah Asian Games 2018 (4-6 } \\
\text { Maret 2018) }\end{array}$ & 13 & 140 & 7 \\
4. $\quad$ Saat ini (27-29 Oktober 2019) & 12 & 1.148 & 45 \\
\hline
\end{tabular}

Sumber: Dokumentasi Pribadi (2019)

Berdasarkan hasil wawancara dengan para key informan, motivasi volunteer Asian Games 2018 selain ingin terlibat dalam momen bersejarah, juga ingin ikut merasakan euphoria kebersamaan, menyukai bidang olahraga, serta keinginan untuk mengembangkan skill kepemimpinan dan kerja sama. Selain itu key informan juga menyampaikan adanya indikasi penyalahartian dan penyalahgunaan istilah volunteer baik oleh kelompok milenial maupun para event organizer.

Penyebutan kata volunteer kini semakin marak digunakan dan merujuk kepada kelompok orang-orang yang aktif dan berjiwa sosial tinggi. Kelompok milenial berlomba-lomba mendaftarkan diri pada berbagai event yang membutuhkan volunteer. Sebelum Asian Games 2018, event-event organizers di Indonesia cenderung menggunakan kata crew daripada volunteer. Namun kelompok milenial kini lebih ingin disebut sebagai volunteer daripada crew. Meski demikian kata volunteer sendiri disalahartikan dengan tetap mengharapkan fee (wawancara dengan Yasiinta Anggraeini di Central Park, Jakarta Barat pada tanggal 3 Oktober 2019 pukul 14.50 WIB).

Sejalan dengan pernyataan Yasiinta, Nanda menyatakan semakin sulit menemukan volunteer yang tulus membantu dengan jiwa relawan yang tinggi. Saat ini, beberapa kelompok milenial cenderung lebih berorientasi kepada uang sebelum memutuskan bergabung dalam kegiatan event volunteering (wawancara dengan Nandami Mahargina di Mal Metropolitan, Bekasi pada tanggal 17 Oktober 2019 pukul $11.00 \mathrm{WIB})$.

Kesuksesan perekrutan volunteer Asian Games 2018 telah menjadikan kata volunteer sebagai suatu kata eksklusif di mata kelompok milenial. Mengambil kesempatan ini, beberapa event organizers yang identik dengan kata crew kini berlomba-lomba membuka perekrutan untuk volunteer yang justru menyalahgunakan arti kata volunteer. Sonia melihat kini beberapa event organizers yang membutuhkan pekerja murah mengemas kata crew menjadi volunteer dengan tujuan menarik minat kelompok milenial (wawancara dengan Sonia Marcellina di Paris Van Java, Bandung pada tanggal 21 Oktober 2019 pukul 14.40 WIB).

Selanjutnya peneliti akan melakukan interpretasi data dengan mengkaitkan data yang ditemukan dengan teori-teori yang digunakan dalam penelitian ini. E. 
Shannon dan Warren Weaver dalam Hafied Cangara mendefinisikan komunikasi sebagai bentuk interaksi manusia yang saling mempengaruhi baik disengaja maupun tidak. Bentuk interaksi tidak terbatas dalam penggunaan bahasa verbal saja tetapi juga dalam mimik wajah, lukisan, seni dan teknologi (Cangara, 2010). Berdasarkan hasil wawancara diketahui bahwa komunikasi menjadi hal yang esensial dalam perkembangan event volunteering sebagai bagian dari gaya hidup kelompok milenial. Komunikasi banyak dilakukan melalui teknologi media yaitu grup WhatsApp memudahkan interaksi antar kelompok milenial yang terlibat dalam event volunteering. Kelompok milenial pun terpengaruh satu sama lain melalui komunikasi dan informasi-informasi yang disampaikan baik secara sadar maupun tak sadar.

Kathleen J. Turner menyatakan adanya hubungan timbal balik antara budaya populer dengan media massa (Ibrahim, 2011:xxxvii). Berdasarkan hasil wawancara para key informan dan informan mengakui pengaruh kuat media massa khususnya new media dalam perkembangan popularitas event volunteering. Menurut Dito, media massa khususnya media-media sosial sangat berpengaruh dan membantu penyebaran tren atau popularitas event volunteering semakin cepat di kalangan milenial (wawancara dengan Dito Ariotedjo di Grand Sahid Jaya, Jakarta Pusat pada tanggal 8 November 2019 pukul 15.14 WIB).

Terdapat hubungan erat antara event volunteering sebagai suatu budaya populer dengan media massa khususnya new media dalam hal penyebarannya. Hal ini juga sesuai dengan pernyataan Brent D. Ruben dan Lea P. Stewart bahwa komunikasi bermedia memberikan kontribusi budaya yang sangat besar. Media massa telah lama memainkan peran penting dalam pengemasan dan pengiriman informasi budaya (Ruben dan Stewart, 2014).

Menurut KBBI daring kata komersial memiliki arti sesuatu yang berhubungan dengan niaga atau perdagangan. Adapun pengertian komersialisasi dalam KBBI adalah perbuatan yang menjadikan sesuatu sebagai barang dagangan (https://kbbi.web.id diakses pada tanggal 20 November 2019 pukul 20.22 WIB).

Kegiatan komersialisasi dalam event volunteering mempunyai dua kepentingan, yaitu kepentingan publik dan sponsor. Namun kini dilakukan juga demi kepentingan kelompok milenial dan panitia penyelenggara. Hal ini sesuai dengan pandangan Zulhasril mengenai antusiasme kelompok milenial atas kegiatan event volunteering didasari adanya unsur komersial dan keinginan untuk diekspos, dikenal dan divisualisasi sebagai sosok yang baik. Adapun Zulhasril menyoroti pergerakan event organizer dimana ketika mengadakan suatu acara didasari oleh profit atau keuntungan sebanyak-banyaknya dan ini kemudian dijadikan bisnis yang terus berkembang (wawancara dengan Zulhasril Nasir di Universitas Tarumanagara, Jakarta Barat tanggal 14 Oktober 2019 pukul 12.28 WIB).

Zulhasril menyatakan bahwa kecenderungan event volunteering untuk menjadi bagian dari gaya hidup kelompok milenial bergantung pada banyak tidaknya kesempatan itu di masyarakat. Bila banyak diadakan dan ditemui oleh milenial dalam kehidupan sehari-harinya, kegiatan event volunteering dapat dikatakan sebagai bagian dari gaya hidup milenial (wawancara dengan Zulhasril Nasir di Universitas Tarumanagara, Jakarta Barat pada tanggal 14 Oktober 2019 pukul 12.28 WIB). Sedangkan Dito menyatakan bahwa tawaran mengikuti event volunteering di Indonesia saat ini sudah banyak. Menurut Dito secara keseluruhan event volunteering sudah menjadi bagian dari gaya hidup kelompok milenial saat ini (wawancara dengan Dito Ariotedjo di Grand Sahid Jaya, Jakarta Pusat pada tanggal 8 November 2019 pukul 15.14 WIB). 
Plummer dalam Nugroho J. Setiadi mengungkapkan tiga aspek penting untuk mengevaluasi gaya hidup, yaitu apa yang dirasakan, sikap dan opini orang atas berbagai fakta yang ada (Setiadi, 2015). Bila merujuk pada pendapat Plummer tersebut maka terungkap bahwa event volunteering sudah dapat dikatakan menjadi bagian dari gaya hidup kelompok milenial karena aspek perasaan, sikap dan opini seluruh key informan relatif positif terhadap kegiatan event volunteering.

Kelompok milenial merasa senang ketika terlibat dalam kegiatan event volunteering dan merasa sedih ketika tidak dapat terlibat dalam kegiatan event volunteering yang diinginkan. Kelompok ini rela menjadikan event volunteering yang diikuti sebagai prioritas utama, misalnya para volunteer Asian Games 2018 yang sudah bekerja, rela mengambil cuti hingga keluar dari pekerjaan tetapnya agar dapat berkontribusi penuh untuk Asian Games 2018. Menurut key informan, kegiatan event volunteering banyak memberikan manfaat positif dan telah menjadi wadah pengembangan diri. Namun mereka juga menyayangkan tindakan penyalahgunaan kata volunteer untuk pencarian keuntungan dari beberapa pihak dan menyarankan perlu adanya batasan jelas antara crew dan volunteer agar tidak lagi terjadi penyalahgunaan kata volunteer dalam penyelenggaraan kegiatan event volunteering.

Gaya hidup erat kaitannya dengan citra diri atau self image. Hal ini sejalan dengan pendapat Ibrahim yang menyatakan bahwa pilihan gaya hidup yang diciptakan dari sekian banyak yang ditawarkan di masyarakat adalah hasil dari pergulatan diri dalam pencarian identitas dan kepekaan terhadap lingkungan sekitar. Anthony Giddens menambahkan bahwa identitas diri merupakan suatu hasil yang diwujudkan. Hasil ini dipahami oleh masing-masing orang dengan caranya sendiri dan dicapai dengan cara berbagi cerita mengenai diri sendiri (Ibrahim, 2011:149-150). Kelompok milenial yang menjadikan event volunteering sebagai bagian dari gaya hidupnya cenderung membentuk citra diri yang positif, misalnya memposisikan diri sebagai seorang pemimpin, seorang yang berpengalaman, peduli dengan lingkungan dan dikagumi oleh orang-orang disekitarnya. Citra diri ini terbentuk dari keterlibatannya dalam kegiatan event volunteering yang bersifat positif. Citra positif tersebut juga terbentuk karena mereka senang dan sering berbagi cerita mengenai pengalamannya selama terlibat dalam kegiatan event volunteering.

\section{Simpulan}

Pertama, peningkatan popularitas event volunteering di kalangan kelompok milenial berhubungan erat dengan media massa dan relatif didominasi oleh new media daripada media konvensional. Di Asian Games 2018 penyebaran informasi didukung melalui new media maupun media konvensional dan cenderung meningkatkan minat dan antusiasme kelompok milenial terhadap kegiatan event volunteering. Kedua, terdapat komersialisasi dalam kegiatan event volunteering yang ditujukan untuk kepentingan publik dan sponsor event. Namun kini juga kerap ditemui pada beberapa pihak panitia penyelenggara dan kelompok milenial penggiat event volunteering. Ketiga, event volunteering telah menjadi bagian dari gaya hidup kelompok milenial karena relatif sudah sering ditemui dalam kehidupan sehari-hari kelompok milenial. Alasan lainnya adalah karena aspek perasaan, sikap dan opini kelompok milenial yang relatif positif terhadap kegiatan event volunteering. Keempat, kelompok milenial menjadikan event volunteering sebagai bagian dari gaya hidupnya karena akan membentuk citra diri positif sebagai sosok yang baik, aktif dan dikagumi oleh orangorang di sekitarnya. 


\section{Ucapan Terima Kasih}

Peneliti ingin mengucapkan banyak terima kasih kepada para key informan (Kak Laras, Kak Yasiinta, Kak Orryandhi, Kak Sonia, Kak Nandami) dan informan (Kak Tara, Profesor Zulhasril, Kak Dito) yang telah bersedia meluangkan waktu dan memberikan informasi yang diperlukan dalam penelitian serta teman-teman dan keluarga yang telah memberi dukungan kepada peneliti.

\section{Daftar Pustaka}

Badan Pusat Statistik. (2018). Statistik Gender Tematik: Profil Generasi Milenial Indonesia. Agustus 26, 2019. https://www.kemenpppa.go.id/lib/uploads/ list/9acde-buku-profil-generasi-milenia.pdf

Cangara, Hafied. (2010). Pengantar Ilmu Komunikasi (Ed. Revisi). Jakarta: Rajawali Pers.

Hasil Pencarian - KBBI Daring. (n.d.). diakses pada tanggal 20 November 2019 pukul 20.22 WIB. https://kbbi.web.id

Herdiansyah, Haris. (2014). Metodologi Penelitian Kualitatif untuk Ilmu-ilmu Sosial. Jakarta: Salemba Humanika.

Ibrahim, Subandy. (2011). Budaya Populer sebagai Komunikasi: Dinamika Popscape dan Mediascape di Indonesia Kontemporer. Yogyakarta: Jalasutra.

Musick, Marc. A. dan John Wilson. (2008). Volunteers: A Social Profile. Bloomington: Indiana University Press.

Nazir, Moh. (2011). Metode Penelitian. Bogor: Ghalia Indonesia.

Nelly, Nelly. dan Suzy S. Azeharie. (2018). Foto Prewedding Sebagai Bagian dari Gaya Hidup. Agustus 19, 2019. Jurnal Koneksi, Vol. 2, No. 1, Hal: 132-135. https://journal.untar.ac.id/index.php/koneksi/article/view/2440

ProfilInstagram @idvolunteering. (n.d.).diakses pada tanggal 28 Oktober 2019 pukul 18.33 WIB. https://www.instagram.com/idvolunteering/

Ruben, Brent D. dan Lea P. Stewart. (2014). Komunikasi dan Perilaku Manusia (Ed. 5). Jakarta: Rajawali Pers.

Setiadi, Nugroho J. (2015). Perilaku Konsumen: Perspektif Kontemporer pada Motif, Tujuan, dan Keinginan Konsumen. Jakarta: Prenadamedia Group.

We Are Social dan HootSuite. (2019). Digital 2019: Indonesia. September 20, 2019. https://datareportal.com/reports/digital-2019-indonesia 